\title{
Prevalence and characteristics of apical aneurysm in hypertrophic cardiomyopathy: a prospective analysis of cardiac magnetic resonance findings and clinical outcomes
}

Sang-Chol Lee ${ }^{* *}$, Eun Kyoung Kim', Sung-A Chang ${ }^{1}$, Sung-Ji Park', Yeon Hyeon Choe ${ }^{2}$, Sung Mok Kim², Seung Woo Park', Jae $\mathrm{K} \mathrm{Oh}^{3}$

From 18th Annual SCMR Scientific Sessions

Nice, France. 4-7 February 2015

\section{Background}

Hypertrophic cardiomyopathy (HCM) with apical aneurysm (AAn) is associated with considerable morbidity and mortality. However, the real incidence of AAn tends to be underrecognized due to the poor visualization of left ventricular (LV) apex with echocardiography. This study sought to investigate the exact incidence and clinical manifestations of AAn in patients with HCM.

\section{Methods}

A total of 350 consecutive patients diagnosed with HCM (mean age $54 \pm 12,278$ males) underwent cardiac magnetic resonance (CMR) and echocardiography. All enrolled patients were prospectively followed up for adverse clinical events including cardiac death, admission for heart failure and cerebrovascular accident. We divided the subjects into 4 phenotypes according to the location of hypertrophic segment; asymmetrical septal hypertrophy (ASH), apical, concentric and septal/apical type. On CMR, the LV volumetric parameters were measured, and the amount of late gadolinium enhancement (LGE) was calculated with grayscale thresholds of $6 \mathrm{SD}$ above the mean signal intensity for normal remote myocardium. Echocardiographic evaluations included left atrial volume index, mitral inflow pattern, tissue Doppler of mitral annulus and LV dimension. Median follow up duration was 37 months.

\section{Results}

The prevalence of AAn on CMR was $14.3 \%$, which was significantly higher compared to previously reported data. AAn was detected in all groups of HCM regardless of type (16.8\% in ASH type, $15.3 \%$ in apical type, $17.9 \%$ in concentric type, and 9.1\% in septal/apical type of HCM). Clinical manifestations and LV volumetric parameters on CMR did not differ between the HCM patients with and without AAn. The frequency and the amount of LGE were not different between two groups (frequency; $94 \%$ vs. 93.3\%, $\mathrm{p}=1.00$, extent; $11.7 \pm 8.9$ vs. $13.0 \pm 10.3, \mathrm{p}=0.43$ ). During follow up, the frequency of adverse clinical events did not differ between patients with and without AAn $(\mathrm{p}=0.259)$.

\section{Conclusions}

The incidence of AAn in HCM patients was far higher than it was reported previously. Regardless of presence of AAn, initial manifestations and associated morphology of LV were similar. This means that adverse clinical outcomes in HCM patients with AAn may be a long-range problem which arises from secondary myocardial changes due to AAn.

\section{Authors' details}

'Dept. of cardiovascular Meidicine, Samsung Medical Center / Sungkyunkwan Unicersity, Seoul, Korea (the Republic of. ${ }^{2}$ Radiolgy, Samsung Medical Center / Sungkyunkwan University, Seoul, Korea (the Republic of.

${ }^{3}$ Cardiovascular Medicine, Mayo Clinic, Rochester, MN, USA. 
Submit your next manuscript to BioMed Central and take full advantage of:

- Convenient online submission

- Thorough peer review

- No space constraints or color figure charges

- Immediate publication on acceptance

- Inclusion in PubMed, CAS, Scopus and Google Scholar

- Research which is freely available for redistribution

Submit your manuscript at www.biomedcentral.com/submit
C Biomed Central 